\title{
May the evidence be with you...
}

Citation for published version (APA):

Kramer, B. W. W. (2011). May the evidence be with you... Maastricht University. https://doi.org/10.26481/spe.20111006bk

Document status and date:

Published: 06/10/2011

DOI:

10.26481/spe.20111006bk

Document Version:

Publisher's PDF, also known as Version of record

\section{Please check the document version of this publication:}

- A submitted manuscript is the version of the article upon submission and before peer-review. There can be important differences between the submitted version and the official published version of record.

People interested in the research are advised to contact the author for the final version of the publication, or visit the DOI to the publisher's website.

- The final author version and the galley proof are versions of the publication after peer review.

- The final published version features the final layout of the paper including the volume, issue and page numbers.

Link to publication

\footnotetext{
General rights rights.

- You may freely distribute the URL identifying the publication in the public portal. please follow below link for the End User Agreement:

www.umlib.nl/taverne-license

Take down policy

If you believe that this document breaches copyright please contact us at:

repository@maastrichtuniversity.nl

providing details and we will investigate your claim.
}

Copyright and moral rights for the publications made accessible in the public portal are retained by the authors and/or other copyright owners and it is a condition of accessing publications that users recognise and abide by the legal requirements associated with these

- Users may download and print one copy of any publication from the public portal for the purpose of private study or research.

- You may not further distribute the material or use it for any profit-making activity or commercial gain

If the publication is distributed under the terms of Article $25 \mathrm{fa}$ of the Dutch Copyright Act, indicated by the "Taverne" license above, 
Inauguration of Dr. Boris W.W. Kramer October $6^{\text {th }}, 2011$

Boris W. Kramer, MD, PhD

Professor of Experimental Perinatology

Maastricht University Medical Center, Neonatology,

School of Oncology and Developmental Biology

School for Mental Health and Neuroscience,

University of Maastricht, The Netherlands

May the evidence be with you...

Rector magnificus, dean, vice-dean, members of the faculty, colleagues, students, family and friends.

Thank you very much for coming to Maastricht to listen to this inaugurational speech.

An inauguration is an introduction of a new professor to the public and the University of Maastricht. But what am I doing as a professor of the university? It is not summarized in one word since I am busy in four difference areas:

1 teaching,

2 patient care,

3 research and

4 management. 
And the evidence in all of those business areas is different. This will be the subject of my inaugurational speech. It is the tradition to do this in this kind of a presentation.

Let us start with the core business of a university: teaching. The University of Maastricht was founded some 40 years ago, as a new element to the Dutch academic situation. The teaching was designed around problem orientated learning. What will you remember from such a speech, where I will be talking for 45 minutes and you will be listening for 45 minutes? It is only $5 \%$ that you will remember! To put it in numbers: of the 40 slides I will show, you will remember 2. Pick them wisely!

The University of Maastricht has driven all efforts to get the best motivations into their students. Why? Motivated students learn, irrespective of the form and environment they are being exposed to. Motivated students pick up from speeches like this, but they also profit, if they are working with their hands on - or teach others. The motivation of the students is therefore the holy grail.

We have to look to preserve that, to increase that and to cherish this motivation. How is the University of Maastricht trying to accomplish that? With the C's and with the S's. Teaching has to be constructive and it has to be context related. It has to increase the collaboration among the students and it has to go for the ultimate self-guided, self responsible and independent learning. All this will increase the intrinsic motivation of the students. But how is this implemented? Skillslab is the secret! The students get, in a very context related environment, their hands on patient simulations. They have supervision and feedback - and can easily try to do it again. They are not learning out of books and all over sudden they suffer the practical shock of seeing a patient. That is in short the evidence and the whole concept of preparing 
young people for a life long learning experience. That is where the teaching by a professor comes into play which involves teaching to medical students, internships during medical school, hands on with real patients, final year rotations, mentoring people with which specialty they should spend the rest of their professional lives, teaching residents, who will advance the field of your clinical practice, training fellows and giving continuing medical education to recognized specialists in the field.

Patient care is coming all along in these teaching. I am a neonatologist. I am specialized to take care of such preterm babies. A preterm baby can be two hands full of life, less than 1000 grams in birth weight. Such a baby is taken out of the natural environment 3 months to early. It is born at 28 weeks instead of 40 weeks of gestation. The child is in acute danger either to die or not to reach the potential it is carrying in it. The baby will spend some 3 months outside the natural environment in the neonatal intensive care unit, with more light and noise levels than in the uterus, with higher cortisol levels in its blood and it has still the potential to grow into a healthy, complete human being. With all the potential of human being; being intellectual, psychological, physical and social potentials.

Preterm birth is the most important single course for mortality and morbidity in our societies. Figure 1 shows the numbers from the United States how expensive it is - in terms of lost household and labor market productivity. This is a very American way to approach it. 


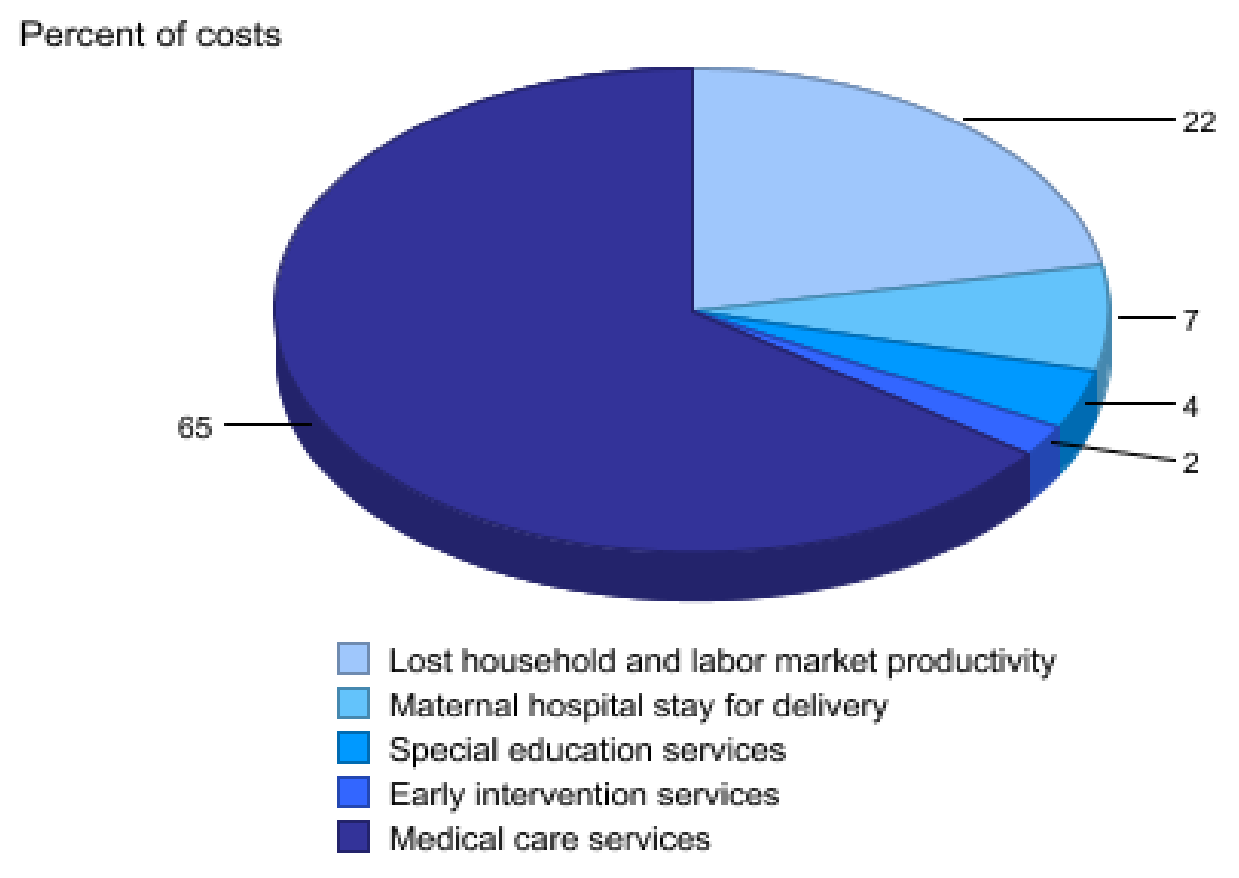

(9) 2009 March of Dimes Foundation. All rights reserved.

Figure 1: $\quad$ Distribution of \$26 billion social economic costs of preterm birth in the United States of America in 2005. Source: Institute of Medicine. 2007. Preterm Birth: Causes, Consequences, and Prevention. National Academy Press, Washington, D.C. Published and unpublished analyses.

Medical services is what we would to be more concerned about. But is it alright to talk about money in those context? When I started to study, some 20 years ago, it was an absolute inadequate question. However, times have changed and the economical departments of the health care ministries will do the calculations. But these calculations are not made public. The following considerations I owe to Lex Doyle, who is a professor at the University of Melbourne, and who has done these calculations for the Australian Health Care system (Figure 2). It is a cost-utility analysis. It answers the question how much money you have to take in your hands for one patient to get one extra healthy year of live. This is the quality adjusted live year here. It 
is not survival, but it is quality of survival that this is measuring. Or to put it this way. I will ask you know, how much money would you be willing to pay to get one healthy year of life, if you were suffering a stroke. We are talking about hundred thousands of Australian dollars. Are you willing to sell your car for that? With a stroke unit 130.00 Australian dollars will buy you one extra healthy year. If you have a major cardiac infarction, it will cost you a sports car. But what about oncology? That is what we are most afraid of. Oncology is rather cheap with this. What would you expect now, after you heard those risks, that babies die or that they survive, but their survival is bought with a lot of handicap. The neonatal intensive care unit is cheap. Why that? If there is a healthy survivor, you are talking of decades of life expectancy.

\section{Cost-utility analysis: $\quad$ Additional costs per patient}

\section{Aus-\$}

Additional quality-adjusted life year (QALYS)

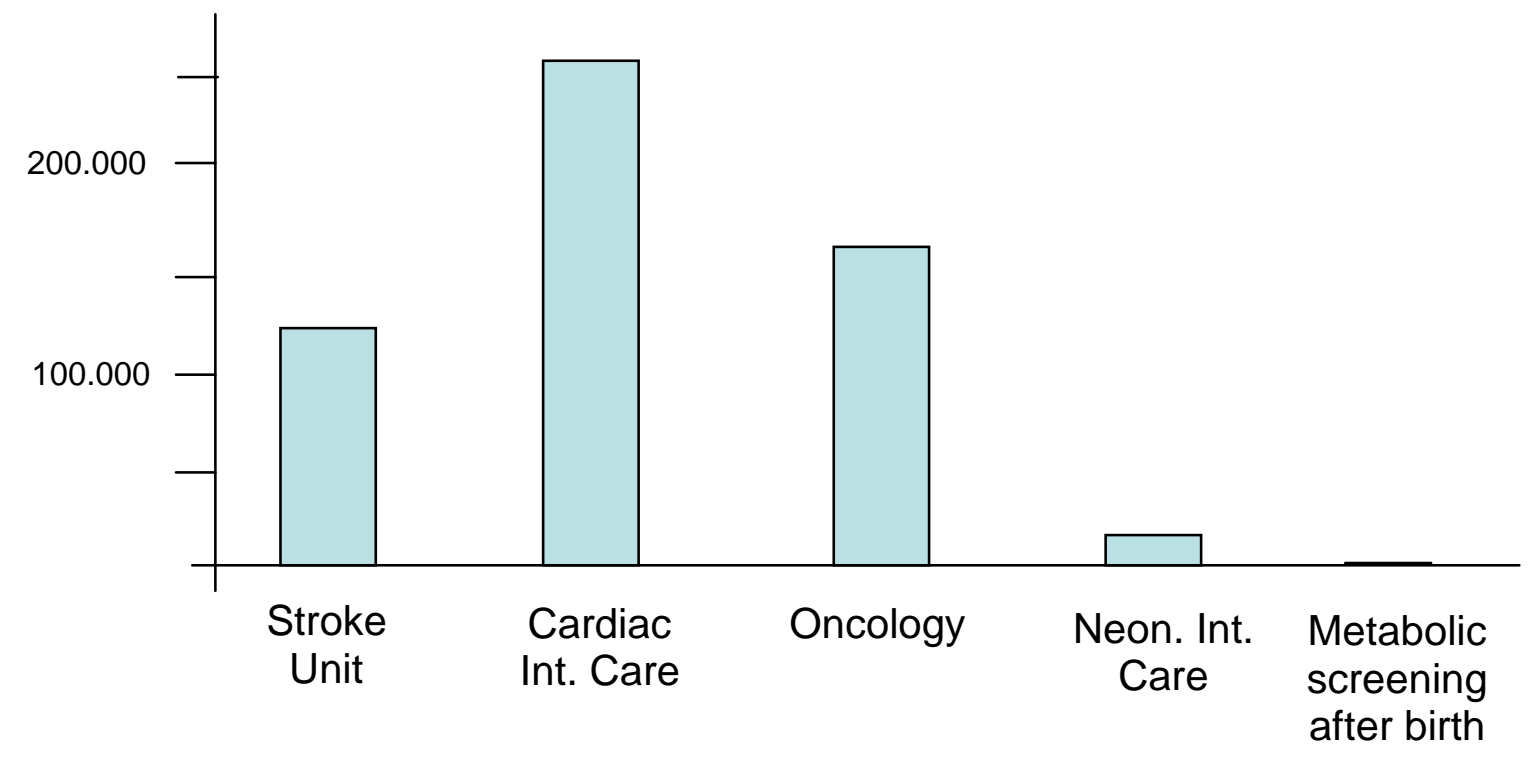

\section{Courtesy of Prof. Dr. Lex Doyle}

Figure 2: $\quad$ Cost-utility analysis for health care in Australia. The costs of an additional year of quality-adjusted life year are displayed. 
That is the reason why, if you compare this to adult care, the neonatal intensive care unit is so cost effective. Or to put it in a positive way. Your Euro's are well invested into a successful reproduction, which is in the end the only successful solution for an aging society.

Pediatrics has been the pace-maker for prevention. There is a mandatory program that every newborn child has to give several drops of blood. Those drops of blood will be tested for the presence of some components, that indicate that this child will suffer a metabolic disease in the following years to come - which means a problem for life time. For example, if you don't have enough thyroid hormone, you will suffer a persistent problem in your brain development. This can be easily detected in the first days of life and it is very easy to treat by giving the missing hormone. Even if you screen all newborn babies and only one in 4,000 or 100,000 is being picked up, it is a cost effective strategy as shown in figure 2 -= because you prevent disease instead of treating it. Therefore, adult medicine focuses onto prevention.

When I made this title "May the evidence be with you ....." everyone immediately replied: You are talking about evidence based medicine. Yes, and this is only part of my daily work. I have four business areas to cover. Evidence-based-medicine is an analysis technique of existing data to extract the evidence gained from the clinical methods, to allow us to take better clinical decisions. It seeks to access the strength of evidence and the risks and benefits of treatments. " Is it safe?", is the first question that every patient asks you, if you want to introduce new treatments. There are different qualities of evidence: systematic reviews, double-blinded placebo controlled randomized clinical trials, conventional wisdom or authority based medicine. The latter is from the old days. The old days are very nicely summarized by Johann Wolfgang 
von Goethe who said: "If you survive the treatment of your doctor, you recognize that his expert opinion of today will be the common errors of tomorrow."

I want to give you an example of evidence-based medicine in my field of neonatology. When a baby is born prematurely, it is missing surfactant. Surfactant is an abbreviation for "surface active agents". It is a complex mixture of lipids and proteins, that is reducing the surface tension in the smallest units of the lung, called the alveoli. In fiure 3 you see a lung without surfactant and it will induce an airflow from the small alveoli into the large alveoli. If we have surfactant the airflow stops and it will be stabilized.

\section{Surfactant stabilizes alveoli}

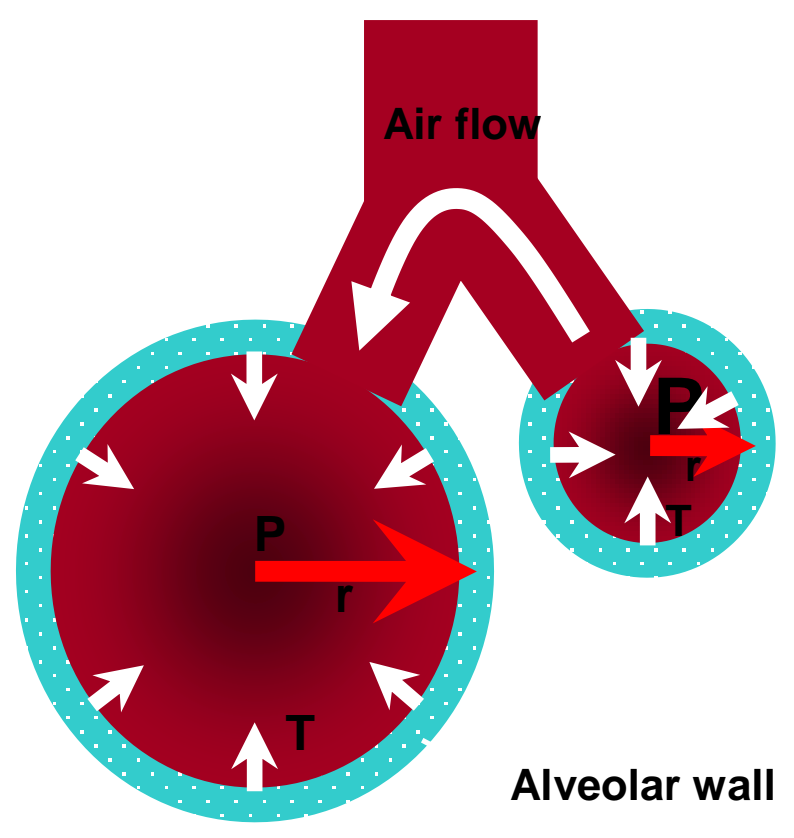

Without Surfactant

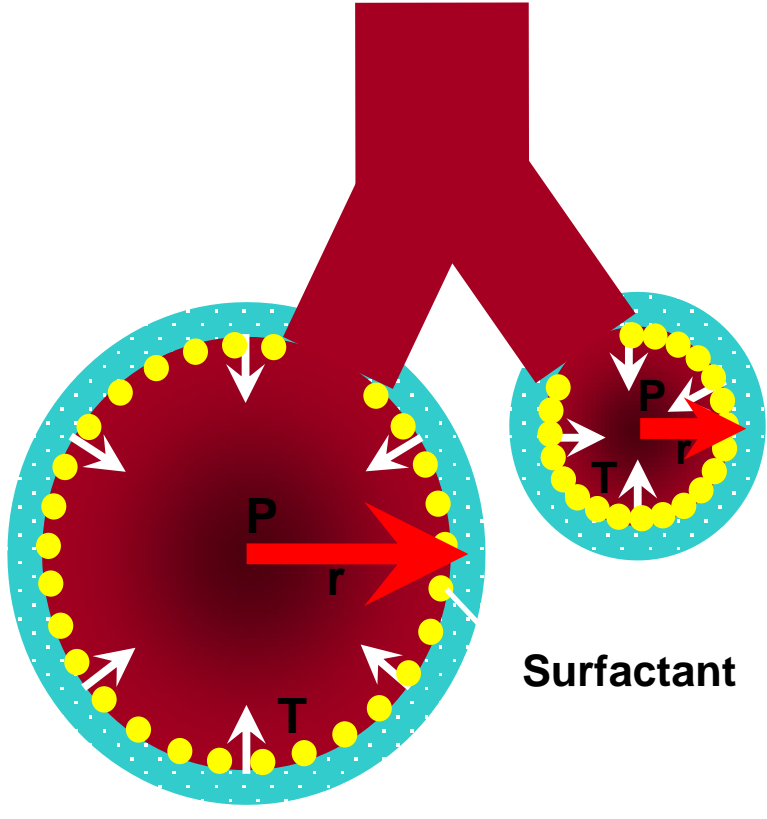

With Surfactant

Figure 3: In the absence of surfactant, small alveoli will collapse. 
I ask you: is this intuitive? Do you accept this immediately? I did not as a student. What do you do then? An experiment! If we connect two balloons with a three-way stopcock, we can model this situation. If we inflate one ballon a lot and the second one only a little, we mimic the situation: The small alveoli is completed sucked out. All the air will go into the large lung until it is completely overextended and will rupture. That is what is causing the mortality and morbidity after preterm birth, if those babies develop respiratory distress syndrome. It is my pleasure to have Alan Jobe, Mikko Hallman and Luc Zimmermann today here in the audience, who have been pioneers in developing the surfactant replacement therapy and the underlying basic lung biology. The surfactant therapy looks easy, when it is working. You take surfactant, you install it under sterile conditions into the preterm baby and this baby will have a smoother lung and will avoid the over distension of the alveoli. But how much do you give? My former mentor, Christian Speer, did clinical trials testing doses between one hundred and six hundred milligrams/kilogram body weight. He found, that one hundred milligrams is the minimum, two hundred milligrams are slightly better, but above two hundred there is no additional benefit. This is the way, how evidence is being generated, and this evidence can help us in our clinical judgement. I want to give you another example, what it means to have evidence. Our preterm babies are born out of a complication of pregnancy which is called chorioamnionitis. This is a diagnosis by the pathologists saying: when I look at the membranes after such a pregnancy I see neutrophils. It is a straight forward observational diagnosis. Chorioamnionitis is extremely common in our preterm babies and is caused by bacteria, that have invaded the amniotic cavity. Do antibiotics help in such a situation? 
There was a randomized, double-blinded clinical trial, which was absolutely well designed, that aimed at comparing two antibiotics: one was amoxicillin \& clavulanic acid and the other one was erythromycin. They did not only compare the short term outcomes, but they invested even into long-term follow-up, up to seven years of age. The devastating result was, that all those babies who have been treated intra uterinely with Erythromycin did worse than the ones that were treated with a penicillin. Meaning, erythromycin did not do any good, it even did not help at all. What was happening? This is a clinical study that fulfils the highest requirements for evidence-based medicine, but the underlying biology was wrong. If you take an old textbook about pharmacology it says that erythromycin does not cross the placenta in high concentrations to harm bacteria. It cannot reach the fetus whom you would like to treat. We have high levels of evidence-based medicine, clinical insignificant, because the biology was wrong.

What do we want to teach our students, residents and fellows? We want to teach them patient care, but to actually do this really well, they must understand the mechanisms of disease, but also have to know the mechanisms of research. Science is a integral part of our training and if I think this further on, we should not only teach our students how to learn, how to increase their intrinsic motivation, but we should also teach them "Leading in learning how to do research". That is a vision, an idea - but it is the core business we should be looking at.

The research that I am doing with my group is translational research (figure 4). We are taking clinical observations from bedside and move it to the bench, where experimental research is being done. But in the end the translational research can only be successful, if the loop is being closed. You move from the bed to the bench side and from the bench side back to the bed, to 
really improve the care for patients. If you took this into a longitudinal perspective, it is laboratory research, it is translational research resulting into clinical research and population research which finally changes the public health strategy (figure 4). That is where our research is being organized.

\section{Translational research: From bedside to bench ... and from bench to bedside!}

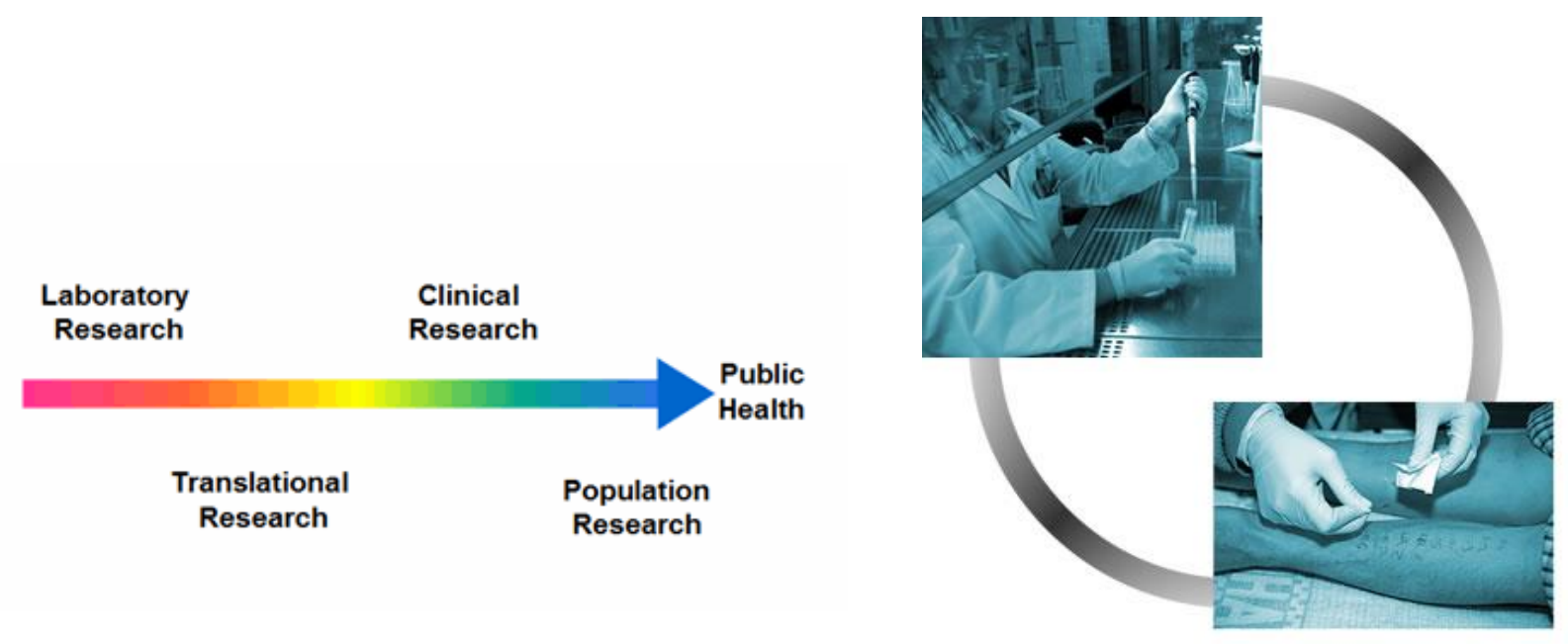

Figure 4: $\quad$ Schematic overview of translational research.

I will cover 5 topics of this research. The first one is chorioamnionitis and I will present you why we think this is a multi-organ disease of the fetus. The second will focus on the fetus as a patient, if we treat him or her already in uterus. The third is that cell based therapies may change the way how we think of outcome, how this translation can be made into clinical care and how we already try to change clinical practice as the last topic. 

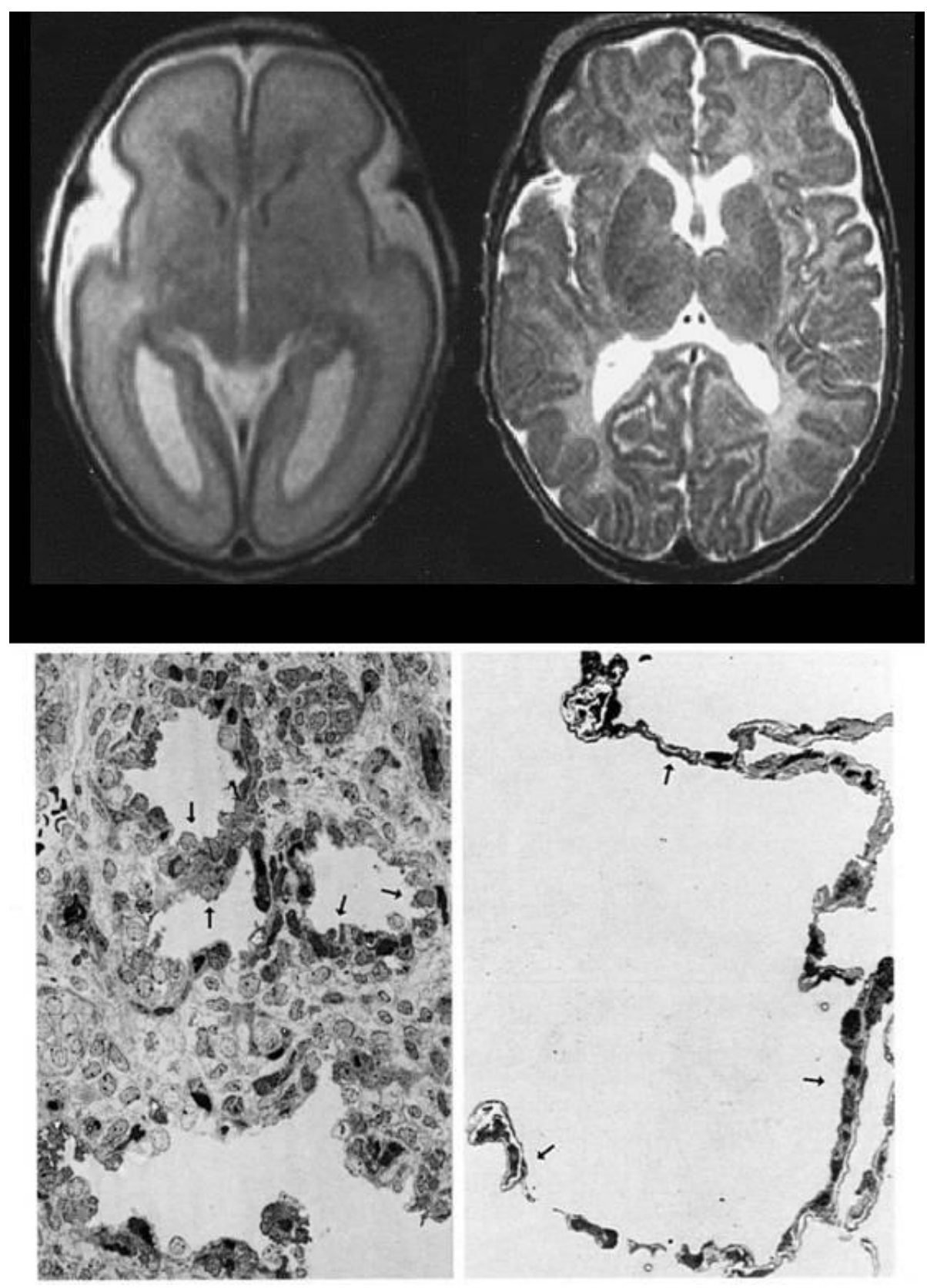

24.

40. weeks of gestation

Figure 5: $\quad$ Top row: MRI images of the brain at 24 weeks and 40 weeks of gestation. Lower row: histology of lungs at the same gestational age. 
Chorioamnionitis is a description, it says "yes", there is an inflammation in the membranes. But we do not know when it starts, we don't know which bacteria is causing it and we do not know how the fetus has already been responding to it. If you think we can do a culture of the amniotic fluid, it is an expensive idea, and you can only culture $5 \%$ of all known bacteria. The rest cannot be cultured, so you are technically blind on this aspect. Why is this so important?

In figure 5 you see pictures of the brain of this child at 24 weeks and how the brain should look like if this baby had the chance to stay in uterus and go through to term gestation at 40 weeks. Similar pictures for the lung.

The most common outcome after preterm birth is a delay in lung development which is called bronchopulmonary dysplasia (BPD). The lung structure is simplified and the resulting gas exchange area for the lung is diminished. If the gas exchange area is reduced through which you have to channel your oxygen demand then you have to make sure that you get more oxygen with the help of a higher gradient. That explains the diagnosis of supplementary oxygen for a baby with BPD. In experiments this simplified lung structure was easily induced by fifteen days of starving. Interestingly, the structure of the lung was almost returned to normal after reintroducing feeding. There is a big plasticity and that is the hope for us as doctors and for the babies. How is this growth driven? It is a four dimensional problem: the lung has to know at which area a new alveolus should be sprouting out and at what time point. This structural information is in the elastin deposition, and one of my PhD students Elke Kuypers has nicely named it, elastin is the structural navigation system of the lung. The concentrated deposition of elastin means: Here is the next branching turn left, grow in this direction. Without the concentrated deposition of elastin this information is lost, probably forever. This is an 
interesting point to look at, if we want to understand why some babies develop that and how we can actually reverse that. We need a good model, that is close to the human biology, where actually the lung is developing in the human context, where the gut is developing in the human context and where the brain is developing in the human context. Unfortunately, rodents, rats or mice are different. On the other hand, we would have the transgenic technology to study genes in the timely defined fashion: switch on genes, switch off genes in a sophisticated and deliberate way.

The subject of chorioamnionitis has been introduced to me by my mentor Alan Jobe and by Suhas Kallapur, whom I met 12 years ago, when I went as a post doc at Children's Hospital in Cincinnati, Ohio, USA. This is a collaboration that is almost worldwide with John Newnham at the University of Western Australia, in Perth. We have been studying the development of chorioamnionitis namely with respect to the lung and the immune system. If we induce a chorioamnionitis, which is the advantage of an animal model, that you can control everything: be it the gestational age of the fetus, be it the stimuli which are inducing this chorioamnionitis. Then you get a cascade in the lung of injury of inflammation, apoptotic remodeling with subsequent proliferation. The surfactant pool has been increased and that gives the babies probably the survival benefit if they are being exposed to chorioamnionitis. But there is a price tag to this benefit. The growth of the lung is already impaired after 7 days of chorioamnionitis. The blood and air containing parts of the lung have been impaired in their new growth and reduced alveologenesis and microvascular is the price that is being inflicted. There is a complex immune modulation being induced. For example, a preterm baby does not have alveolar macrophages. Alveolar macrophages are generated at the end of pregnancy when blood 
derived monocytes come to the lung, become residential and with a master switch they are being told: you will be an alveolar macrophage. We are able to demonstrate that this is being induced in prematurity where chorioamnionitis also induces complex dysregulation of the immune system which can be summarized as Endotoxin tolerance. The immune system is hibernating, it does not response to the second stimuli of Endothoxin. Whether this is good or bad is the research question of the moment. I want to highlight what the students in my lab have been doing in these aspects, these are the PhDs of Jennifer Collins and Elke Kuypers. They are looking at the elastin, the structural navigator of the lung. The concentration of elastin is dense and perfect, the lung knows where to go. If the information is lost to some extent, it is unclear what will happen. No structured, no focused elastin deposition prevents future lung growth. This is an example of the research and synergies that the facility of the campus has induced. When we started to establish this chorioamnionitis model in sheep, I asked among my colleagues in neonatology, who would be interested to collaborate with me. I am very grateful to Eduardo Villamor, who is a specialist on vascular reactivity. We looked at the vascular reactivity and his PhD-student Rob Moonen showed that the vasculature of the gut, after being exposed to chorioamnionitis, is impaired in its relaxation. This was put together by Tim Wolfs, at that time a PhD-student with Wim Buurman. That was the first description of chorioamnionitis inducing profound functional and structured changes in the gut. That is the explanation of clinical data we have had before we heard from an epidemiological study that chorioamnionitis is a risk factor for necrotizing enterocolitis. This a risk factor for adverse outcome of the gut. We are very happy to continue this collaboration with Wim Buurman's lab and also with Nicolaus Gassler's group in Aachen. This is also the first example of many successful collaborations between Aachen and Maastricht. 
Ronit Sverlov is a specialist about lipids and liver diseases. She asked me, what does chorioamnionitis mean for the lipids. We did research with her post-doc Veerle Bieghs and a PhD-student from the department of pediatrics, Evi Vlassaks. She showed that the disturbances in the gastrointestinal tract after this chorioamnionitis are not limited to the structure of the gut, but it also means that even after 7 weeks a higher concentration of total lipids in the liver can be found. This is a risk factor for subsequent disease and may be a new idea how developmental origin of health and disease has to be looked at. Elke Kuypers, Jennifer Collins and Stefan Kunzmann from Würzburg have a special interest in the immune cells. At present they are looking at the powerhouse of the immune system, the thymus. This is the site where in fetal life the immune system is maturing. This is a unique period in life, where the whole differentiation of T-lymphocytes is happening. The composition of the fetal thymus is profoundly changed in the presence of chorioamnionitis.

Another example for a successful collaboration between the University of Aachen and Maastricht is the study of airway reactivity after chorioamnionitis. It is my pleasure to welcome the dean of the medical faculty of Aachen, professor Stephan Uhlig and his colleague professor Christoph Martin from the department of pharmacology, today in the audience. We have been working together with my PhD-student, Verena Lambermont, on airway reactivity after preterm birth and after exposure to chorioamnionitis. Verena took a special interest and asked a very basic question: does the gender matter in the response to chorioamnionitis? Females have a better response with respect to increasing lung gas volume, if they are being exposed to chorioamnionitis. But this is an aspect that we have not paid attention to and additional data 
are needed to guide us. This is the way how we generate hypotheses from experimental research to test them later in clinical databases.

Another example for the collaboration is the PhD project of Monique Engel, who is an accomplished consultant of pediatric intensive care. She studies in adult sheep different recruitment maneuvers.

If you talk to neuroscientists nothing matters more than the brain. To a certain point - they are right. But I still think, that we have to consider the brain not limited to the brain, but to the interaction between the brain and the lung for example, or the brain and the heart. The brain and the gut is completely unstudied and I am very happy that a new initiative in the Research School of Mental Health and Neuroscience is taken to study further these relationships. This research is being done in collaboration with my colleague neonatologist Danilo Gavilanes, his post-doc Eveline Strackx and my PhD-students Elke Kuypers and Reint Jellema. And that is the question: how is the fetal brain affected by this chorioamnionitis? In healthy animals, nerve tractions are going in all directions. At the same age, just 7 days after exposure to chorioamnionitis, most of the connections are lost. To understand how this is happening, without any bacteria being introduced into this organ, without any bacteria or pro-inflammatory stimulus actually reaching the brain, just by systemic inflammatory responses is the subject of this research. Therefore, we have redrawn the cartoon and this is now the cartoon of how we look at it. There are bacteria in the amnionitic fluid, but the fetus is not only breathing in and out and causing a pulmonary inflammation, but it is also swallowing the contaminated amniotic fluid and it induces many diseases be it in the lung, in the brain, or in the gut (figure 6). That is in 
summary how we think of chorioamnionitis at the moment: as a multi organ disease of the fetus (figure 6). To understand the mechanisms is the aim of this kind of research.

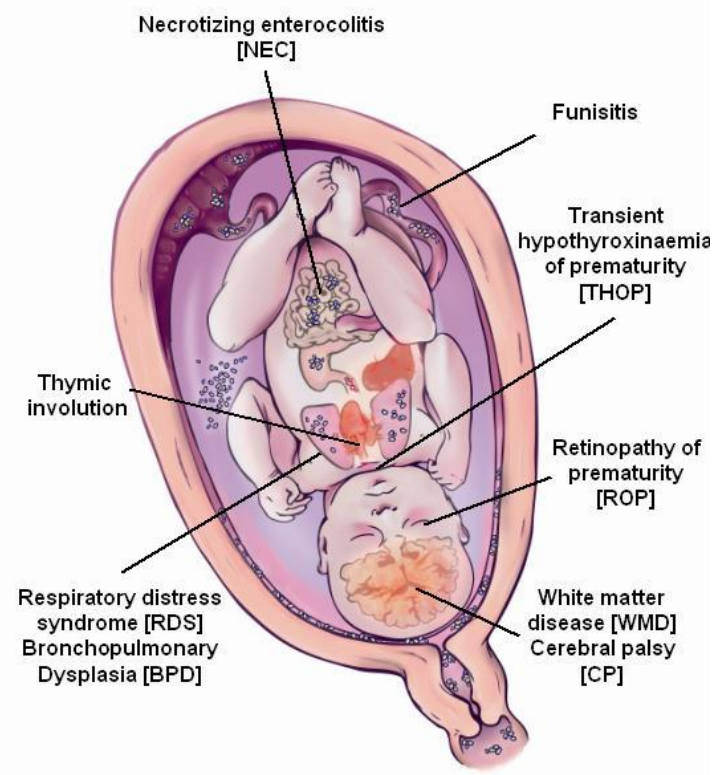

Figure 6: Chorioamnionitis as a multi-organ disease of the fetus. From Gantert, Been, Gavilanes, Garnier, Zimmermann, Kramer, J Perinatol. 2010 Suppl:S21-30.

We are very happy to have Ulrike von Rango, from the department of Anatomy and Embryology, joining our group, because she is a specialist of the placenta. Let us now show an example, how we analyze placental tissue, that was collected by Luc Zimmermann in Rotterdam some 8 years ago. This is research done by Jasper Been in this cohort in Rotterdam. He showed that, if you have been exposed antenatally to chorioamnionitis, your response to surfactant is changed. If you have not been exposed to chorioamnionitis your oxygen requirements quickly drops from $50 \%$ to more or less room air and it stays there. If you have been exposed to 
chorioamnionitis, you respond to surfactant but this response is only transient. Within 2-3 hours you are back to the original need for surfactant. This has been controlled for gestational ages, for gender and other factors. This is an example that chorioamnionitis alters the clinical course of an evidence-based proven method and intervention. That opens a whole new area: would it be then a good idea to use a higher dose of surfactant in those babies? If we had an already better surfactant, that is resistant against an activation? Or should we give medications that have high risks only to babies, that will have a benefit? We need to know within 20 minutes after birth, if a child has been exposed to chorioamnionitis in order to use this information for our clinical judgement. We would have to generate evidence-based clinical interventions on this assumption. In real life, it takes usually two weeks to get the results from the pathologists, if there is chorioamnionitis or not. At that time most interventions have been done and that is the reason why Jasper Been is developing a prediction model to actually use clinical information, that is immediately available after birth, to make a model to assess the risk if a baby is exposed to chorioamnionitis. With this information, in a strategy for clinical trials, interventions can be made possible and a whole new way of clinical care that is more "personalized", can be developed.

Let us go back to the neurodevelopmental outcome. Cerebral palsy is still common and it is a devastating situation. It can be limited to motoric functions, but also means an impaired neurodevelopmental outcome. I am very happy that the Research School of Mental Health and Neuro Science and the Graduate School Euron sponsored a new way of trying to improve outcome. This research has been done together with the Research School of Oncology and Developmental Biology. This is an example that two research schools can work successfully 
together. The basic idea, that the PhD-student Matthias Seehase, formulated was: if we look at the clinical data, we know that the anesthesia of a pregnant woman with Propofol or with Isofloran gas does not make a different in non-emergency c-sections. Most of our clinical csections are however emergency c-sections. The obstetricians have clinical signs that the fetus is not happy and well. These signs indicate that the fetus is suffering from a shortage of oxygen. The question that Matthias asked: Is this also true for an emergency c-section? He induced an hypoxic-ischemic injury in the fetus, that was so bad, that it needed cardiac resuscitation. The whole blood circulation broke down. This is such a severe event, that either the fetus will survive with an impaired neurologic development or it will die. He then studied these two drugs, that have been used in clinical care. This was a collaboration with the group of Tamo Delhaas, to assess the cardiac functions. With all those assessments we were able to show: Propofol is beneficial. For example, Matthias could show that the cell death in the brain was reduced. Thanks to a collaboration with Peter Andriessen, from the Medical Center in Veldhoven, who is an expert in analyzing in an automatic way data that are generated from monitoring of electric functions, we could show that these animals have less seizure activities. Diane Smit, together with Robert Stokroos and Bernd Kremer, showed that the sensoneural hearing loss was also reduced. Lipid metabolism, a collaboration with Otto Bekers, from the internal department, showed that this is not associated with the common problems of Propofol.

Another example for translational research, that we are doing, are the cell based therapies. This is a collaboration between Aachen and Maastricht, a rotation position, between the faculty of medicine in Aachen and the postgraduate school Euron. Reint Jellema is doing his PhD on a basic idea, that cell based therapies can overcome the deadlock in which we are from a clinical 
perspective. The basic question is, if we give stem cells into a preterm lamb after hypoxia nad ischemia, do we see a repopulation of the injured brain tissue by those stem cells? The chances are not bad because the fetus has a tolerant immune system, it has a growth directed environment and an open blood brain barrier. That is the basic idea and question that he presumed and that is the animal model, that he and Marcus Gantert, a PhD student from Obstetrics and Gynaecologists, developed. They have made a maternal and fetal intensive care unit. This fetus is being operated on, with a continuous EEG monitoring, ECG monitor, arterial catheter to measure the blood pressure. Hypoxia and ischemia are induced by a remote occluder several days after operation. When you see that you have induced a severe hypoxic ischemia, then you open up the blood flow again and let this experiment go for 7-10 days. This model was set up by the dedicated help and support from the animal care department and I want to thank in this context Joyce Suyck, who is the responsible leader of the large animals, Saskia Seeldrayers who is the respresentative of the Dutch government for the implementation of the laws governing the animal experimentations and we truly appreciate her and Barry Plooyer's expert opinion on handing those large animals. They have tremendously helped to implement this animal model in a very short period of time.

If you give stem cells of different origins it does not make a difference with respect to brain weight. If you induce the severe hypoxia and ischemia, the brain weight is heavily lowered. If you give stem cells the brain weight loss is less and this is also true with respect to the functional analysis and I owe these data to Peter Andriessen, who is also involved in this project. This is another example, that if you do not have the expertise in your own group look around and you will, especially find in Aachen, Eindhoven and Veldhoven, people who are willing to 
collaborate. Peter Andriessen has formulated it very nicely: If we share our resources, meaning the patients we have to take care of, and the technologies that we understand, we will be very successful. If we do so, yes, we can collaborate and can grow into one organisation.

To give you an example of how many people are involved in the assessment and development of this model, especially with respect to the underlying immunology, I would like to highlight Wilfried Germeraad, whose expertise and group has helped this model tremendously. But these are all the people that are being involved in this one very project. And that makes it clear, this is the strength of this university. People are willing to collaborate and people are willing to share their expertise and knowledge. And I want to highlight this in a more sophisticated way. This is probably one of the most successful collaborations. Jutta Arens is an engineer, who had an idea, how you can improve the oxygenation of babies. And there is a clinician, Marc Schoberer, who is also in the audience and Thorsten Orlikowsky, head of the Neonatology Aachen. With the help of Reint Jellema, Matthias Seehase and Jennifer Collins we collaborated. Now Jutta Arens is an award winning young researcher and engineer. We are now trying to make this work, so that we have alternatives for a cost intensive and very invasive technology called extracorporal membrane oxygenation and which is the last example of a successful cooperation between Aachen and Maastricht.

The most important thing is how we change clinical practice. We are doing our first clinical trials with our colleagues from neonatology in Veldhoven. One of the questions is: How much pressure do you give for stabilizing the lung and airways in preterm babies? We know that with each $\mathrm{cm}$ of pressure some new pneumothoraces occur. Should we give eight, six or four cms of water pressure? This is the dilemma with clinical judgement without evidence. That is the 
reason why we really have to conduct clinical studies, that are well rationalized, well powered to answer those questions and that is the way how we want to continue. Let me summarize: If we share our patients and the technologies that we understand, we can advance and we can advance for the wellbeing of the babies and give them a better helping hand.

Ladies and gentleman, I would not be standing here, if I had not been supported by many people. I want to thank Luc Zimmermann, I would like to thank my colleagues of Neonatology Mark van der Hoeven, Twan Mulder, Pieter Degraeuwe, Eduardo Villamor, Danilo Gavilanes and Jeroen van Hoorn. They have taken me up in their group, when I was coming, unable to speak Dutch, but: ze hebben mij dat wel geleerd om Nederlands te praten. I would like to thank the head of the lab of the department of pediatrics Freek van Iwaarden; his PhD student Coen Willems; Nico Kloosterboer and Lilian Kessels. Without those people we would not be able to take students and introduce them to the joy and pleasure of doing research and experiments and to do these things in a safe way. I want to thank Edward Dompeling, the head of pediatric pulmonology. We are realizing that we are not only looking at the same organ, but also the same kids, just at a different time of life. That is a potential source of collaboration we want to exploit. In this context I also want to thank the developing collaborations with the department of Pulmonology, Miel Wouters and Gernoud Rohde and Nicky Reynaerts, while we are realizing that other pulmonology and neonatal pulmonology maybe the different sides of the same coin. In the end I want to thank Jan Nijhuis and Marc Spaanderman, who will be the head for the obstetric research. We are hoping really for future collaboration that this experimental perinatology can be really expanded to antenatal situations and not only to postnatal situations, where we have at the present the focus on. I want to thank the dean prof. Albert Scherpbier, 
who is also the head of the institute for teaching. When I came here, completely trained in the German system used in giving 45 minutes talks to audiences without any questions, without any remarks, I was in a culture shock. Now, after 5 years, I can talk about this shock and I am now going back to my old university and try to implement problem orientated teaching and learning. I want to thank the previous dean, now the President of the University, prof. Martin Paul, who initiated the toptalent program and I am very happy that most members of this program are here today. It is a very interesting group and we have shared many good ideas and it is now our challenge to make a difference in the course of this university and in the academic development and to pay back the trust that the faculty has put in to us. I want to thank my mentors and the friendship with Christian Speer, Alan Jobe and Suhas Kallapur. I also want to thank my secretary Natascha Vrijhoeven, who has organized this event so beautifully, the members of my group and especially my wife. You had a lot of patience with me. I thank you very much that you have always inspired me to continue this way into academics. You are a very patient and dedicated woman. When she joined me in the laboratory of Alan Jobe and Suhas Kallapur she joined me in the experiments. We have a paper together which was the first award winning paper in my career - thank you very much Susanne! I want to thank my parents. I asked, 25 year ago, my mother being a school teacher and my father being a professor for physical chemistry, what gives you the pleasure in your work? They replied: Working with young people. And I think this is the essence of being a professor. I think that is the dedication I want to pay back to the faculty and to the university and why it is a pleasure to serve as a professor at this university. I have spoken. 